\title{
The Raising Influence of Information Technolo- gies on Professional Training in the Sphere of Automated Driving When Transporting Mined Rock
}

\author{
Andrey Kosolapov ${ }^{{ }^{*}}$, and Sergey Krysin ${ }^{1}$ \\ ${ }^{1}$ T.F. Gorbachev Kuzbass State Technical University, 650000, Vesennyaya 28 st., Kemerovo, Russian
}

\begin{abstract}
Revolutionary changes in the area of production, holding and exploitation of the automobile as a transport vehicle are analyzed in the article. Current state of the issue is described and the development stages of new approach to driving without human participation are predicted, taking into consideration the usage of automobiles for transportation of mined rock in Kuzbass. The influence of modern information technologies on the development of new sector of automobile industry and on the process of professional and further training of the specialists in the sphere of automobile driving is considered.
\end{abstract}

\section{Introduction}

The transformation of automobile industry is coming before our eyes. The transition "from the automobile to automobility" is becoming a common trend. Many traditional automobile producers are gradually changing into "suppliers of mobile services", accumulating digital solutions and additional services. At the same time, more and more IT- giants are appearing in the field. And, Google and Apple are no more the brightest examples here.

On one hand, a human operator (the driver) has more experience in driving so far. They are resourceful and quick-witted in managing force majeure situations on the road. On the other hand, major cases of car accidents are caused by a human factor. A robot, in its turn, is capable of following the algorithm accurately, but it is still to be learnt to deal with nonstandard circumstances. That's why, as many automobile engineers claim, the automobile is going to be driven by a human for a long time, up to 2030 as minimum.

To "exclude" a human from the system of control many IT developers are placing more and more new products in the constantly expanding market. Examples can be seen in [1-6].

Thus, BlackBerry is developing new driver assistants for Ford. They are based on operational system QNX, which has already been used in Ford's onboard media system Sync 3.

IT-giant IBM, which is run by Mark Fields, CEO of Ford, stakes on artificial intelligence system Watson, designed to assist drivers with advanced voice commands. Four "online" prototypes BMW i8 were developed in cooperation with BMW. System Watson will be

\footnotetext{
* Corresponding author: kosolapovav@kuzstu.ru
} 
adopted by Opel and GM to improve their media systems. IBM cooperates with PSA concern and Ford, working on big data, cloud technologies and "smart city".

Transnational corporation Intel is staking on the automobile: its new subdivision Automated driving group has been developing new technologies for transport since December 2016. Along with Delphi, Intel is working on the solutions to automated driving, which are planned to be presented finished to automobile producers.

Having signed numerous partnership agreements with cloud service Azur (also used by TomTom, Renault-Nissan and Toyota), Microsoft set up a massive campaign on application of its software to automobiles: Skype for Business (is already prepared to be installed in Volvo 90 series) and personal assistant Cortana.

Nokia's chart subdivision Here, designed by American Navteq and known as Ovi, was bought by Audi-BMW-Mercedes in 2015. Nowadays the company competes with Apple and Google, designing digital and multilayered maps, necessary for automated driving.

Nvidia, Santa-Clare, takes revolutionary decisions in the area of automated driving and computerized vision. Its processors and supercomputers with neural networks and self-learning technologies were chosen by Tesla, Volvo, Audi and Mercedes-Benz.

Automobile producers became interested in digitization and new services, staking on the future, when automobiles are autonomous, electrical and distributed shared.

2016 was the year of major changes in automobile industry. It became clear that automobile production would develop new business directions, controlled by special subdivisions and affiliates [6-8]. Thus, Smart Mobility (Ford), Moia (Volkswagen concern), Free2Move (PSA), Maven (GM car sharing), Mercedes-Benz Energy and Accumotive (firms controlled by Daimler and responsible for batteries) were established. Volvo company opened sharing subdivision Sunfleet, BMW expanded activities of DriveNow (in Europe), ReachNow (in the USA). Nissan brand tested systems V2G (vehicle-to-grid) to integrate its electric car Leaf in electricity network of the city. FCA concern made an agreement with Waymo, which continued Google Car project. Perhaps, it is a revolution and it has two directions. On one hand, automobile producers go for high technologies. On the other hand, the producers of electronics began opening automobile subdivisions, concluding bargains of billions, increasing the number of departments, working on software for automated driving. Apart from Google and Apple with Android Auto and CarPlay, respectively, there are a lot of other famous names that are ready to take automotive industry as their major business. Alexander Kotouc, the Head of Product Management BMWi, stated "Automobile industry, in its usual meaning, is already dead. Automobility is our future" [6].

Thus, it's time to speak about new level of opportunities for passenger traffic - mobility 2.0. It means that new requirements appear for specialists, providing the transportation of passengers and freights in various spheres, including those where the exclusion of human participation will significantly raise the level of industrial security and effectiveness. The approach to specialist training ought to be changed adequately.

\section{Materials and methods}

Specialists, working in the area of transportation, already need to know the principles of modern artificial intelligence technologies in terms of their application to transportation sector. Such technologies ought to be based on interaction of rational intellectual agents in common environment (fig. 1) [9, 10].

Artificial intelligence in terms of passenger and freight transportation is expected to include such segments as "autonomous" vehicles, "intelligent" infrastructure and the systems of control. At the same time, the technologies used for autonomous vehicle driving, will be based on $[5,11]$ :

- numerous sensors and intercorporate communication of types $\mathrm{V} 2 \mathrm{~V}, \mathrm{~V} 2 \mathrm{I}$ and $\mathrm{V} 2 \mathrm{C}$; 
- artificial neural networks for big data processing;

- making decisions according to constantly qualifying rules and logics.

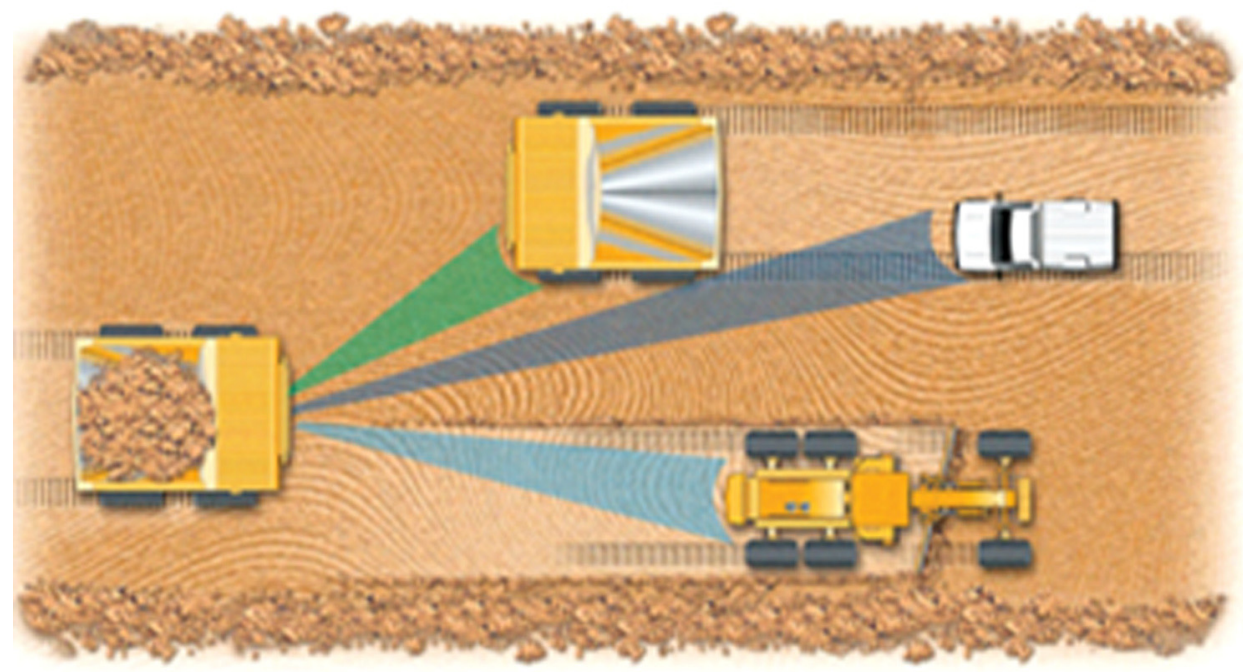

Fig. 1. Representation of traffic as interaction of separate agents in the common information environment.

Road infrastructure is to be integrated in the system of traffic control in a balanced manner.

The current tasks on introduction of artificial intelligence methods into transportation sector are the following:

- the intellectual analysis of big data,

- the developed system of decision making for the control of complicated objects and processes.

The development of information technologies along with the progress in automobile components designing enabled to classify the levels of automated driving. The Society of Automotive Engineers, USA (SAE), defines 6 levels of automated driving, from first assistants, now available even with low-budget economy cars to almost autopilot vehicles [12]. Each level differs by progressive increase of tasks and responsibility transferred from the driver to vehicle electronic systems.

Level 0 represents the systems of forward collision or even of automatic braking, when the vehicle actively interferes with driving. The driver is in complete control of the driving (fig. 2). 


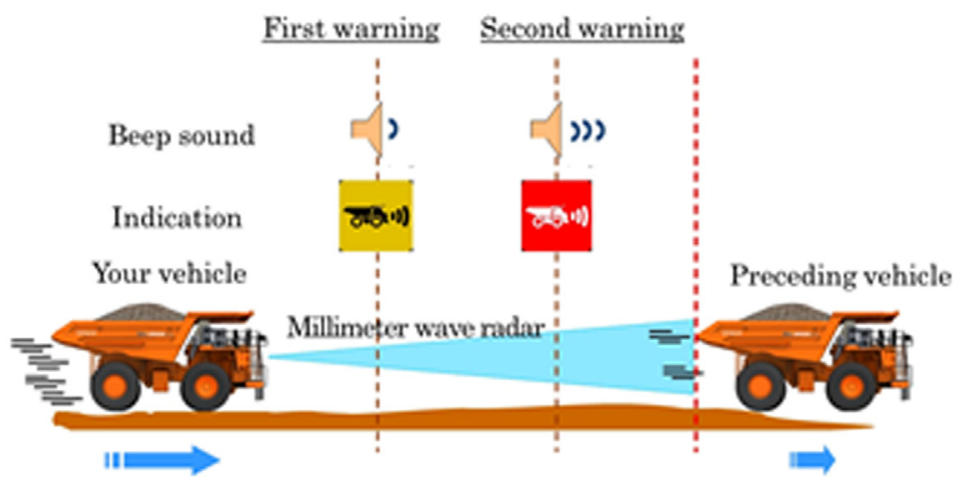

Fig. 2. Level 0. No automation. The driver is in complete control of the vehicle.

Automobile begins cooperating with a human on level 1. Limited number of tasks can be committed to electronics, for instance, active cruise control. However, a human has total control over driving (fig. 3).

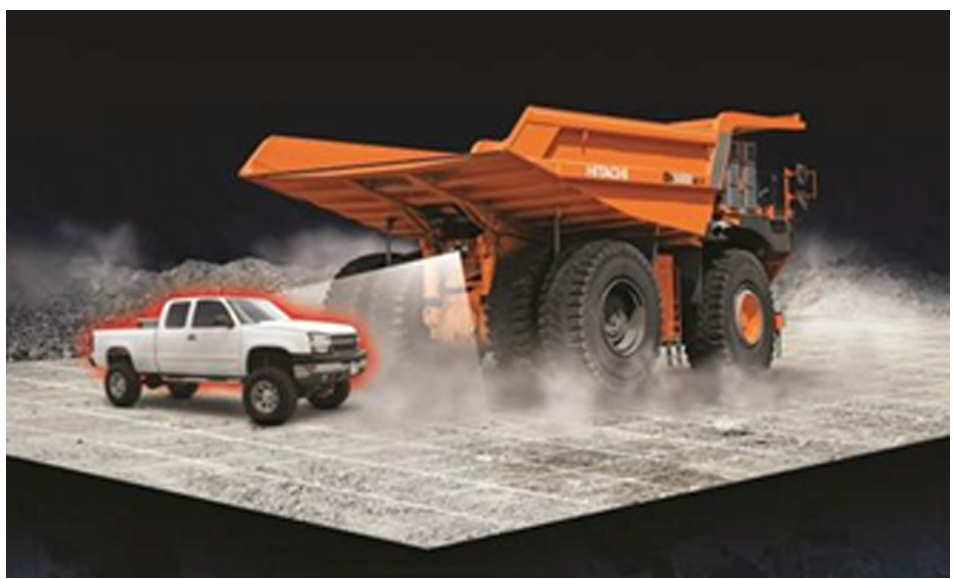

Fig. 3. Level 1. Driving with the assistance: electronics only assists.

Level 2 represents modern stage of automated driving development. In certain conditions (for example, while driving in the countryside or if there are clear road markings) the automobile is able not only to keep distance, accelerating and decelerating, depending on the speed of the cars in front, but also to keep the track, staying in the traffic. The driver ought to keep his hands on the steering wheel to provide safety. The human remains the only one responsible for motion and any strategic decision taken.

A sudden leap to automated driving is expected on level 3. The artificial intelligence of the automobile fulfills the task of monitoring the road situation and in certain conditions makes a strategic choice, for example, to take over or to turn, to enter primary roads and etc. The human can take his hands off the steering wheel and temporarily look away but he ought to be ready to take control if situation occurs to be too complicated for electronics. Time horizon is 2018 .

In certain conditions the automobile is able to control all driving processes on level 4. The human can drive by himself, but in case he fails or makes a mistake, the system corrects them with the help of the correct decision system. The driver is allowed to take his hands off the steering wheel, look away from the road and relax. However, the driver presence is obligatory as there are still some traffic or weather conditions, when system fails. Time horizon is $2020-2025$ (fig. 4). 


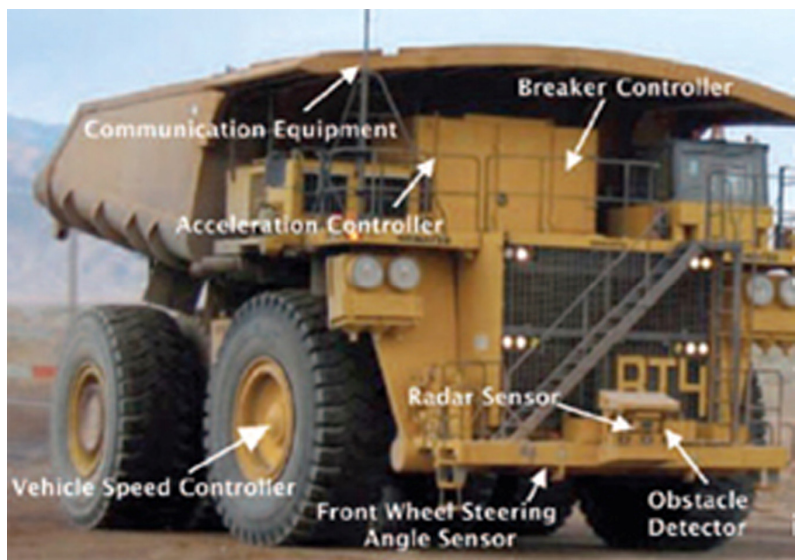

Fig. 4. Level 4. High automation: almost autonomous vehicle (e).

Finally, level 5. It is assumed that the automobile will manage all phases of a trip by itself. The driver won't play any role. The driver presence as well as a steering wheel is no longer needed. Mainly, this level is oriented at transportation systems. Time horizon is 2025-2030 (fig. 5).

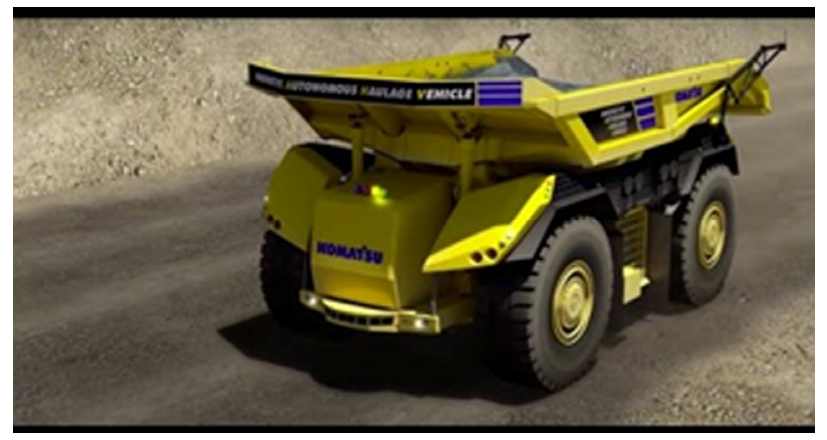

Fig. 5. Level 5. Full automation: driver presence is no longer needed.

Certainly, "big data" processing will play one of the leading roles. "Big data" is usually defined as a huge amount of data in terms of its volume, diversity, transfer rate and degree of reliability that requires special technologies and methods of analysis to extract valuable information.

Autonomous automobiles are required to have various tools of reality perception: shortrange and long-range radars, medium-range lidars, ultrasonic sensors and cameras [12-13]. As a result, the artificial intelligence of the automobile is capable of producing such virtual images, where automobiles, cyclists, motorcyclists and pedestrians are shown as "cubes" of different colours. Virtual bars on the carriageway indicate deceleration zone and braking (fig. $6)$. 


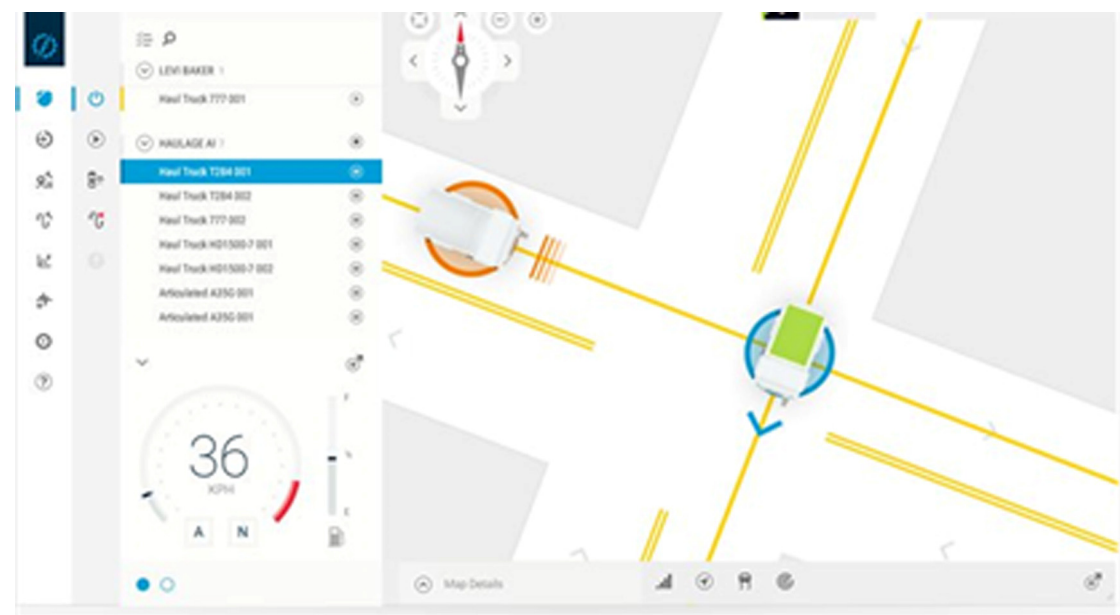

Fig. 6. Virtual presentation of real crossroad.

There are some examples of attempts to introduce autopilot vehicles. Autonomous truck Volvo was put into operation in a Sweden mine in September 2016. According to JSC "KAMAZ", robotized trucks are to be used to fulfill the tasks of mining and other industries in our country in 2020 . The representatives of the system designing company stated, that the operation of robotized dump trucks is economically sound now and is possible only for the fulfillment of special tasks in certain conditions, where the presence of humans is limited and the operation of machinery is conditional on safety requirements and economic feasibility. One of such industries is mining.

One more domestic example is launching a pilot root of "MatrËshka" bus, which is to run round the campus of Far Eastern Federal University on Russkiy island. "MatrËshka" is a totally autonomous vehicle, designed by Scolkovo residents. It allows transferring passengers and freights and can be used as municipal machinery. The designer ensures that autopilots are safer than traditional buses as a human factor, causing car accidents, is excluded, and the artificial intelligence monitors the technical state of the vehicle and reports all malfunctions to the owners.

\section{Results and discussion}

It is assumed that in Kuzbass as a major region known for its open cut mining, automated driving can be used for mined rock transportation. The motion of the dump truck is influenced by fewer factors comparing to its motion in rural conditions. The stability of transportation root, the exclusion of conflicts with other participants of the traffic due to their absence, comparatively low speed - all these factors are to simplify the development of driving algorithms.

However, it requires changes in the list of subjects and the curriculum, taught in T.F. Gorbachev Kuzbass State Technical University. It is obvious that the number of subjects and systems of knowledge, learnt by specialists in traffic organization, ought to include not only information technologies but also such disciplines as "big data" management, neural networks and artificial intelligence. The disciplines that ought to be paid special attention may include "Automatics and telemechanics in traffic", "Computer engineering and networks in the industry", "Informatics", "Information technologies in transportation", "Computer technologies in traffic organization" and "Applied programming in traffic". 


\section{Conclusion}

Modern development of automobile industry, forced not only by consumers' needs but also by the change of the approach to exploitation, holding and even driving the automobile, gets a new vector of development, aiming at the exclusion of the man as an operator. One of the gravest revolutions in freight and passenger transportation, comparing to the revolution in information transfer in the society, will happen in the nearest future.

\section{References}

1. N. Fleming, New Scientist, 206:2754, 34 (2010)

2. J. Weyer, R. D. Fink, F. Adelt, Safety Science, 72, 199 (2015)

3. D. J. Fagnant, K. M. Kockelman, Transportation Research, 77, 167 (2015)

4. M. Schellekens, Computer Law \& Security Review, 31:4, 506 (2015)

5. C. Katrakazas, M. Quddus, W. Chen, L. Deka, Transportation Research Part C: Emerging Technologies, 60, 416 (2015)

6. W. Payre, J. Cestac, P. Delhomme, Transportation Research Part F: Traffic Psychology and Behaviour, 27, 252 (2014)

7. A. Alessandrini, A. Campagna, P. Delle Site, F. Filippi, L. Persia, Transportation Research Procedia, 5, 145 (2015)

8. H. Martínez-Barberá, D. Herrero-Pérez, Transportation Research Part C: Emerging Technologies, 39, 94 (2014)

9. D. J. Fagnant, K. M. Kockelman, Transportation Research Part C: Emerging Technologies, 40, 1 (2014)

10. L. C. Fernandes, J. R. Souza, G. Pessin, P. Y. Shinzato, D. Sales, C. Mendes, M. Prado, R. Klaser, A. C. Magalhães, A. Hata, D. Pigatto, K. C. Branco, Jr. V. Grassi, F. S. Osorio, D. F. Wolf, Journal of Systems Architecture, 60:4, 372 (2014)

11. Quattroruote, 26 (2017)

12. J. Alonso, V. Milanés, J. Pérez, E. Onieva, C. González, T. Pedro, Transportation Research Part C: Emerging Technologies, 19:6, 1095 (2011)

13. S. Le Vine, A. Zolfaghari, J. Polak, Transportation Research Part C: Emerging Technologies, 52, 1 (2015) 
